\title{
Basal Cell Carcinoma Arising from an Epidermal Cyst: When a Cyst Is Not a Cyst
}

\author{
Jia Li Liau ${ }^{a} \quad$ Davide Altamura $^{a} \quad$ Marzena Ratynska $^{b} \quad$ Roberto Verdolini $^{a}$ \\ Departments of ${ }^{a}$ Dermatology and ${ }^{b}$ Pathology, The Princess Alexandra Hospital Trust, \\ Harlow, UK
}

Key Words

Basal cell carcinoma $\cdot$ Cyst $\cdot$ Benign

\begin{abstract}
Malignant degeneration within epidermal cysts is very rare. However, these lesions may not be recognised clinically, and histological examination plays an important role in arriving at a correct diagnosis. Hence, we believe that benign-looking cystic lesions with a history of progressive growth should be surgically excised and submitted for histopathological assessment.

(c) 2015 S. Karger AG, Basel
\end{abstract}

\section{Introduction}

Epidermal cysts are benign cysts derived from the epidermis or epithelium of hair follicles. They can occur anywhere on the skin and often appear as firm and well-demarcated dermal nodules. Malignant degenerations within epidermal cysts are very rare [1-5]. Case reports exist which emphasise the connection between basal cell carcinoma and epidermal cysts as both may arise from the infundibular portion of hair follicles [2, 3]. Here, we report the case of a basal cell carcinoma arising from an epidermal cyst.

\section{Case Report}

A man in his 50s presented to our department with a long history of a cystic lesion on the left shoulder which had rapidly grown in size over the previous 3-4 months. On physical

KARGER 125/s $\quad \begin{aligned} & \text { Jia Li Liau, MB, BCh, BaO } \\ & \text { Department of Dermatology } \\ & \text { The Princess Alexandra Hospital Trust } \\ & \text { Hamstel Road, Harlow, Essex CM20 1QX (UK) } \\ & \text { E-Mail JL1086@ doctors.org.uk }\end{aligned}$


Liau et al.: Basal Cell Carcinoma Arising from an Epidermal Cyst: When a Cyst Is Not a Cyst

examination, there was a firm, movable, well-demarcated, voluminous dermal nodule. On the basis of these clinical findings a working diagnosis of epidermal cyst was favoured, and the lesion was subsequently enucleated under local anaesthetic due to its progressive increase in size.

Macroscopically the cyst, which was $35 \mathrm{~mm}$ in diameter, was lined by a thick wall and contained a whitish lobulated nodule measuring $25 \mathrm{~mm}$ in its largest diameter (fig. 1). Histology revealed a cystic basal cell carcinoma arising from the lining of an epidermal cyst (fig. 2). Immunochemistry showed lack of expression of BerEp4 in the cyst's squamous epithelium but strong positivity on the nodular portion (fig. 3), in keeping with the diagnosis of basal cell carcinoma.

\section{Discussion}

Malignant tumours arising from epidermal cysts are rare [1-5]. The incidence of tumours originating from epidermal cysts is estimated at around $1 \%$ in the literature, with about $70 \%$ of them being squamous cell carcinomas and only about $10 \%$ of them being basal cell carcinomas $[3,5]$. The possible common origin from the infundibular portion of the hair follicle may explain the connection between basal cell carcinoma and epidermal cyst $[2,3]$. Dini et al. [2] described a 55-year-old man with a cystic lesion on the back, which had been present for 20 years and had increased in size during the last year. A diagnosis of a basal cell carcinoma arising in an epidermal cyst was made after histological examination. Ikeda and Ono [3] reported the case of a 78-year-old man who presented with small papules on the upper eyelid present for 50 years. One cyst had grown rapidly and had been partially ulcerated for the last few years. Histological examination revealed an irregularly formed cyst and tumour cell nests developing around it. Both cases reported a lesion which had existed for many years but showed recent rapid growth, with histological examination favouring a diagnosis of malignant transformation. In addition, Delacrétaz [1] reported the case of a basal cell carcinoma arising from an epidermoid cyst which had been present for several years in a 65-year-old woman. Similarly in our case, due to the rapid change in size, the otherwise benign-looking lesion was excised and the histopathology report showed basal cell carcinoma arising from an epidermal cyst.

Given the lack of specific clinical parameters, a basal cell carcinoma arising from an epidermal cyst may not be recognised, and histological examination of these lesions plays an important role in arriving at a correct diagnosis and, consequently, appropriate management. In most cases complete excision is adequate, and recurrence is reported infrequently.

Policy restrictions implemented over the past few years in order to cut National Health Services costs, for so-called 'benign' skin lesions and the revision to the management of 'clinically harmless' cysts, with their referral to specialists and surgical excision having been discouraged, made the treatment of such cases a challenge for both general practitioners and dermatologists. This case, however, demonstrates that a history of progressive growth should prompt proper surgical excision and histopathological assessment even when a cyst might appear clinically benign. 


\section{Case Reports in Dermatology}

\begin{tabular}{l|l}
\hline \multicolumn{2}{l|}{ Case Rep Dermatol 2015;7:75-78 } \\
\hline DOI: $10.1159 / 000381393$ & $\begin{array}{l}\text { C } 2015 \text { S. Karger AG, Basel } \\
\text { www.karger.com/cde }\end{array}$ \\
\hline
\end{tabular}

Liau et al.: Basal Cell Carcinoma Arising from an Epidermal Cyst: When a Cyst Is Not a Cyst

\section{References}

1 Delacrétaz J: Keratotic basal-cell carcinoma arising from an epidermoid cyst. J Dermatol Surg Oncol 1977;3: 310-311.

2 Dini M, Innocenti A, Romano GF: Basal cell carcinoma arising from epidermoid cyst: a case report. Dermatol Surg 2001;27:585-586.

- Ikeda I, Ono T: Basal cell carcinoma originating from an epidermoid cyst. J Dermatol 1990;17:643-646.

4 Tanaka M, Terui T, Sasai S, Tagami H: Basal cell carcinoma showing connections with epidermal cysts. J Eur Acad Dermatol Venereol 2003;17:581-582.

$>5$ Tsujita-Kyutoku M, Danbara N, Yuri T, Nikaido Y, Hatano T, Tsubura A: Basal cell carcinoma arising from a keratinous cyst of the skin: a case report and review of the literature. Med Mol Morphol 2005;38:130-133.

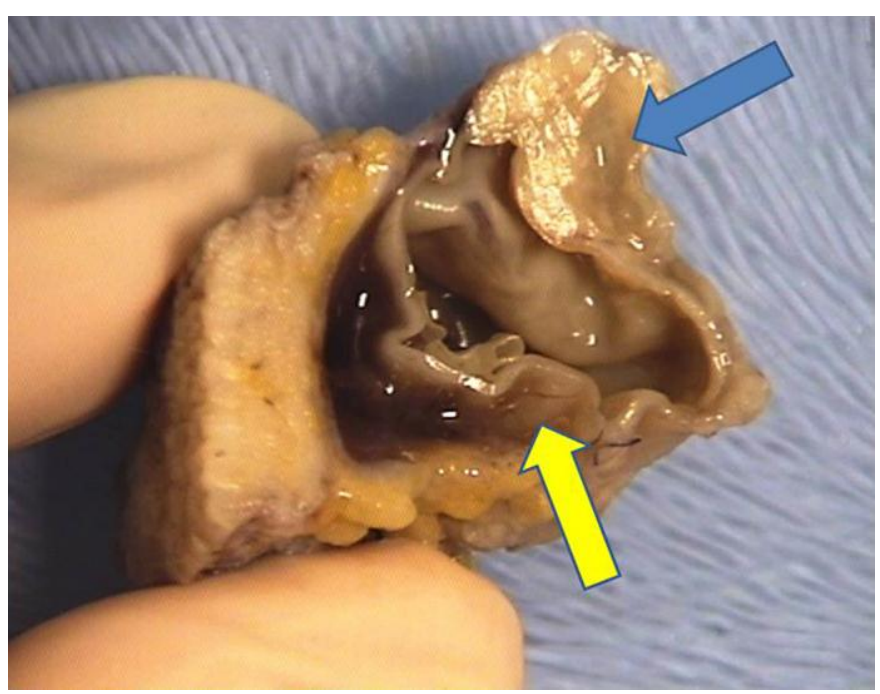

Fig. 1. Macroscopic view of the excised lesion. The original epidermal cyst was almost entirely replaced by the basal cell carcinoma, which had both a cystic (yellow arrow) and solid (blue arrow) component. 
Liau et al.: Basal Cell Carcinoma Arising from an Epidermal Cyst: When a Cyst Is Not a Cyst

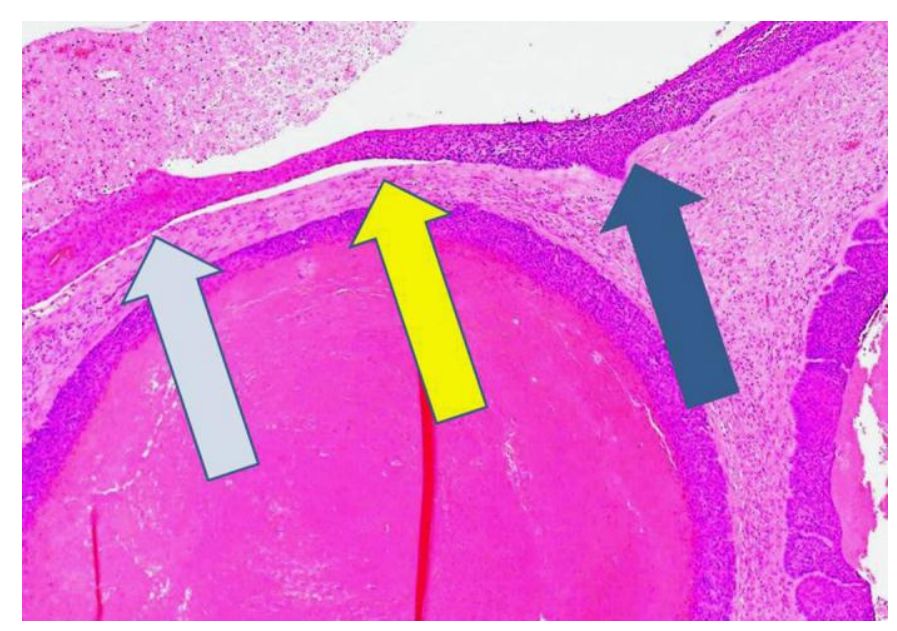

Fig. 2. At low magnification, histology shows the squamous epithelium of the epidermal cyst (light blue arrow) and the basal cell carcinoma (dark blue arrow). The yellow arrow shows the transformation point between the epidermal cyst and the basal cell carcinoma. The rest of the lesion is composed by nodulocystic basal cell carcinoma proliferation. Hematoxylin and eosin. Magnification $\times 20$.

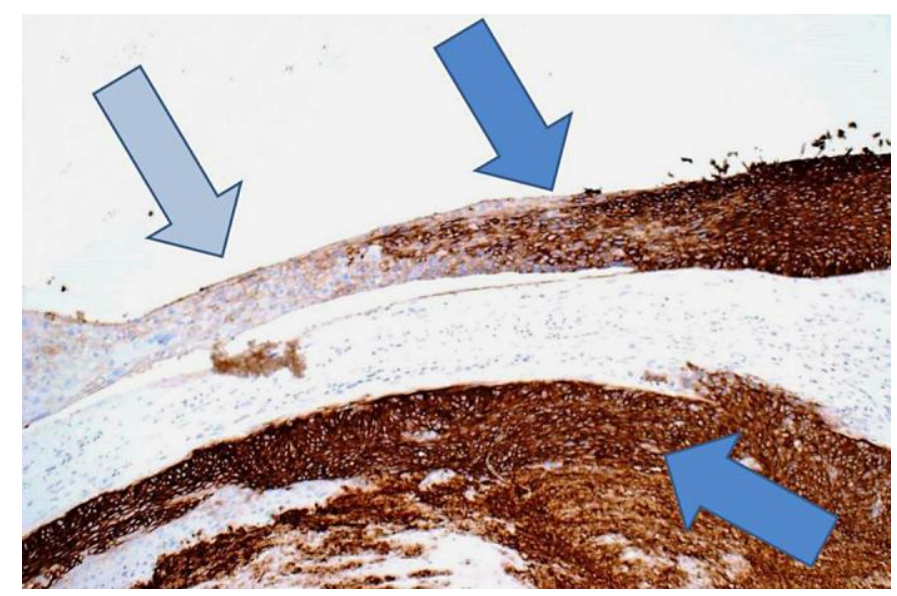

Fig. 3. Immunostaining for BerEp4, which represent a specific marker for basal cell carcinoma cells, clearly reveals the basal cell carcinoma component of the lesion (dark blue arrows). The remnant of the epidermal cyst (light blue arrow) is negative. Magnification $\times 40$. 